\title{
Measuring technical efficiency and frontier intervention for farm machinery manufacturers using slacks-based data envelopment analysis
}

\author{
Manoj Kumar ${ }^{1, *}$, M. B. Tamhankar ${ }^{2}$, Sandip Mandal ${ }^{3}$, V. Bhushana Babu ${ }^{1}$ and \\ Bikram Jyoti ${ }^{1}$
}

${ }^{1}$ Agricultural Mechanization Division, ICAR-Central Institute of Agricultural Engineering, Bhopal 462 038, India

${ }^{2}$ Technology Transfer Division, ICAR-Central Institute of Agricultural Engineering, Bhopal 462 038, India

${ }^{3}$ Agricultural Energy and Power Division, ICAR-Central Institute of Agricultural Engineering, Bhopal 462 038, India

\begin{abstract}
The objective of this study is to estimate technical efficiency of farm machinery manufacturers in Central India. The statistical test for the presence of technical inefficiency has been performed using stochastic frontier production model. Data envelopment analysis (DEA) has been used to identify existing returns to scale in farm machinery manufacturing units. The slacks-based DEA has been used to estimate input excess and output shortfall in the manufacturing system. Results indicate that out of the total variation, $69 \%$ was due to technical inefficiency in the manufacturing system, whereas $31 \%$ was due to stochastic errors. The estimated radius of stability was varied from 0 to 1.74 and the classification (efficient and inefficient manufacturers) was found robust against data alteration within the estimated radius of stability. The results showed that a manufacturer has to increase annual turnover by INR 40.7 million to become efficient.
\end{abstract}

Keywords: Data envelopment analysis, farm machinery, frontier intervention, manufacturers, technical efficiency.

DATA envelopment analysis (DEA) is a linear programming-based benchmarking technique originally developed by Charnes et al. ${ }^{1}$. It measures the relative performance of a decision making unit (DMU) assuming constant returns to scale (CRS), where the presence of multiple inputs and outputs makes comparisons difficult. There are two methods, namely parametric and non-parametric to estimate technical efficiency of a DMU. Stochastic frontier analysis (SFA) is a parametric technique, whereas data envelopment analysis (DEA) is a nonparametric technique to estimate technical efficiency. Both SFA and DEA have advantages and disadvantages. The main advantage of DEA is that it does not need to fulfil any assumption like in SFA. The technical efficiency is measured relative to the best DMU, rather than an average as in case of SFA. However, a DEA-based estimate is

\footnotetext{
*For correspondence. (e-mail: manoj.iasri@gmail.com)
}

sensitive to measurement errors or other noise in the data and the measured technical efficiency is affected by the number of input and output variables, even if they are not contributing to the technical efficiency. The main advantage of SFA is that it takes care of stochastic noise in the data and also allows the testing of statistical hypotheses related to the system. Its disadvantages are that it assumes a parametric functional form representing the underlying model and also assumes an explicit form of distribution for the inefficiency terms. Since the development of the DEA model, this method has been used to evaluate the performance of business firms, regions, etc. ${ }^{2}$. Tone $^{3}$ proposed a slacks-based measure (SBM) of efficiency in DEA. It deals directly with the input excess and output shortfalls of the concerned DMU.

Indian agriculture has marked its presence at the global level. Nevertheless, there are two important bottlenecks like stagnant productivity and shortage of agricultural workers. It has been estimated that use of improved implements can increase the productivity up to $30 \%$ and reduce the cost of cultivation up to $20 \%$ (ref. 4). Indian farmers are adapting improved farm implements than ever before. The percentage of agricultural workers to the total work force was 58.2 in 2001 and it is projected that by 2050 , it would drop to $25.7 \%$ (ref. 5). Farm mechanization through improved agricultural implements can play an important role to tackle the problem of declining agricultural workforce. The quantification of agricultural mechanization for soybean-wheat cropping pattern in Bhopal, Madhya Pradesh, Central India has been done by Kumar et al. ${ }^{6}$. The farm power availability of Central India is about $1.80 \mathrm{~kW} \mathrm{ha}^{-1}$ and it is observed that farmers are getting better net returns from wheat (INR 19,591 ha ${ }^{-1}$ ) followed by gram (INR 18,695 ha $\mathrm{ha}^{-1}$ ) production with a benefit: cost ratio of 1.71 and 1.86 respectively $^{7}$. In this context, the role of farm machinery manufacturers is crucial in the promotion of improved implements. Most of the common agricultural implements in the region are being manufactured by small- and medium-level manufacturers. 
Singh et ll. $^{8}$ studied the status of farm machinery manufacturers in Central India and concluded that majority were small-scale manufacturers $(46.6 \%)$. Most manufacturers of all categories make tractor operated cultivators $(88.14 \%)$, seed-drills $(77.9 \%)$, trolleys $(73.7 \%)$, and threshers $(72.0 \%)$.

Many studies have been conducted on technical efficiency in the agriculture sector. Kumar and $\mathrm{Basu}^{9}$ measured the Malmquist productivity index and its different components like technological change, technical efficiency change and change in scale efficiency in the Indian food industry. Nassiri and Singh ${ }^{10}$ studied energy-use efficiency for paddy producers in Punjab, India, using data DEA technique and concluded that small farmers had high energy ratio and low specific energy requirement compared to larger farmers in paddy farms. Raju and Kumar ${ }^{11}$ evaluated and selected the most suitable irrigation subsystems of the Mahi Bajaj Sagar Project, Rajasthan, India using DEA in both deterministic and fuzzy environments. Maity ${ }^{12}$ studied productivity potentials and efficiencies of the farmers in different states of India utilizing the concept of group and meta frontier technique, and found a large technology gap ratio. Shekhar et al. ${ }^{13}$ studied total factor productivity in India's agricultural sector on the basis of agricultural output and consumption of fertilizers over the period 2004-2005 to 2010-2011. Mathur and Ramnath $^{14}$ examined the efficiency in foodgrains production in India for the period 1960-1961 to 2013-2014 using DEA and SFA. Malhotra ${ }^{15}$ studied financial performance with special reference to working capital management of selected food-processing industries, foodgrains milling, edible oilseeds processing, sugarcane processing and milk processing industries. Taleb et al. ${ }^{16}$ discussed and identified returns to scale (constant, increasing, decreasing) for a public university in Malaysia using output-oriented, integer-valued DEA model. The technical efficiency of farm machinery manufacturers of Central India has not been studied and estimated so far.

In the present study, technical efficiency of farm machinery manufacturers in Central India has been estimated using SFA and slacks-based measure of DEA. The objectives of this study are to measure technical efficiency, identify gaps and provide intervention measures on inputs and outputs for achieving efficient frontier using SBM. The sensitivity analysis has been done using metric approach to measure radius of stability within which the alterations in inputs and outputs will not influence the efficiency status of a manufacturer.

\section{Methodology}

\section{Data source and type}

There were more than 225 manufactures in Madhya Pradesh engaged in manufacturing and sale of different agri- cultural implements ${ }^{17}$. Majority of them $(86 \%)$ were small and marginal with an annual turnover of less than INR 50 million. It was observed that these manufacturers were producing around 45 different implements/machineries used in crop production systems of the region. The information on available infrastructure like number of technicians and helpers, industrial areas, available tools and machinery used in manufacturing farm implements, different agricultural implements manufactured and sale of these implements was collected. This was obtained from 87 manufacturers covering 24 manufacturing hubs located in different parts of Central India.

\section{Data analysis}

The computations were conducted using different procedures in the SAS-9.3 software (SAS Institute Inc., Cary, NC, USA). The linear programming problems for SBM and metric approach of sensitivity were solved using OPTMODEL procedure in SAS. The SAS programs are presented in the Supplementary material.

\section{Output variable}

Annual turnover (million INR): The annual turnover was evaluated for each manufacturer using data on sale of different farm implements during the financial year 2017-18. The markets for these manufactures were located in the same as well as other states of the country. Some manufacturers also exported farm implements to countries like Sri Lanka and Myanmar. Implements like cultivator, seed drill, seed-cum-fertilizer drill, tractor trailer, reversible mould board (MB) plough, leveler and multi-crop thresher were produced by majority of the manufactures. Most of them (85\%) manufactured cultivator followed by seed drill (78\%), tractor trailer $(65 \%)$, reversible $\mathrm{MB}$ plough (43\%), leveler (32\%) and multicrop thresher (29\%)

\section{Input variables}

Number of technicians (TECH): Technicians play a major role in any manufacturing sector. Problem of shortage and unavailability of skilled manpower has been reported by many manufacturers. As the demand for farm implements depends on season, it is necessary to have the required number of technicians during this period. On an average, a manufacturer had four technicians. Although some big manufacturers had more than ten technicians, but the number of such manufacturers was less.

Number of helpers (HELP): Helpers are unskilled workers who work under a technician. Generally, there were two helpers for one technician in a manufacturing unit. 
On an average, a manufacturer had seven helpers to perform the assigned work by their technician, but some large manufacturers had more than 25 helpers.

Number of salesmen (SMAN): The major work of salesmen is to sell the implements, but they are also engaged in advertising implements in farmers' fairs and programmes organized by State and Central Governments to promote farm mechanization. The number of salesmen varied from 1 to 4 depending upon the size of the manufacturing unit.

Number of service staff (SERV): The manufacturers had to provide facility of service after sale for their sold products to the farmers. During the crop season, service staff visit the farmer's fields in service calls. Such type of cooperation helps the manufacturers to market their products and builds a healthy relationship between the manufactures and farmers. The manufactures had one service staff on an average, but some had up to five service staff.

Number of office staff (OSTA): The major work of office staff is to take orders for implements from farmers and other agencies, accounting and record-keeping. They also provide assistance to salesman and service staff. They participate in farmer's fairs and other programmes to advertise their farm implements. Most of the manufacturers had two office staff, while some big manufactures had five or more such staff.

\section{Stochastic frontier analysis}

Stochastic frontier production models were first developed by Aigner et al. ${ }^{18}$ and Meeusen and Broeck ${ }^{19}$. The model is represented in eq. (1) assuming that the production function follows a log-linear Cobb-Douglas model.

$$
\ln \left(Y_{i}\right)=\beta_{0}+\sum_{j=1}^{p} \beta_{j} \ln \left(X_{j i}\right)+v_{i}-u_{i}
$$

where $Y_{i}$ is the Output in the $i$ th DMU, $X_{j i}$ the $j$ th input variable in the $i$ th DMU, and $\beta_{0}$ and $\beta_{j}$ are the unknown parameters to be estimated. The error component $v_{i}$ is assumed to be independently, identically and normally distributed with mean zero and variance $\sigma_{v}^{2}$. If $u_{i}>0$, it represents technical inefficiency and if $u_{i}<0$, it denotes cost inefficiency. The technical efficiency (TE) can be evaluated by eq. (2) assuming $u_{i}$ as a half normal, exponential or truncated normal distribution

$$
\mathrm{TE}_{i}=\frac{Y_{i}}{\exp \left(X_{j i}^{\prime} \beta_{j}+v_{i}\right)}=\frac{\exp \left(X_{j i}^{\prime} \beta_{j}+v_{i}-u_{i}\right)}{\exp \left(X_{j i}^{\prime} \beta_{j}+v_{i}\right)}=\exp \left(-u_{i}\right)
$$

In case of the Cobb-Douglas model, technical efficiency and cost efficiency coefficients are equal.

\section{Empirical stochastic frontier model}

The functional form of the stochastic frontier production model is represented by eq. (3) considering annual turnover (ATO) as the dependent variable, and TECH, HELP, SMAN, SERV and OSTA as the independent variables for each farm machinery manufacturer.

$$
\begin{aligned}
\ln \left(\mathrm{AT}_{\mathrm{i}}\right) & =\beta_{0}+\beta_{1} \ln \left(\mathrm{TECH}_{i}\right)+\beta_{2} \ln \left(\mathrm{HELP}_{i}\right) \\
& +\beta_{3} \ln \left(\mathrm{SMAN}_{i}\right)+\beta_{4} \ln \left(\mathrm{SERV}_{i}\right)+\beta_{5} \ln \left(\mathrm{OSTA}_{i}\right) \\
& +v_{i}-u_{i},
\end{aligned}
$$

where $i$ represents $i$ th the farm machinery manufacturer, and $i=1,2, \ldots, 87$.

\section{Non-parametric DEA model}

DEA model: This includes the constant returns to scale (CRS) model and the variable returns to scale (VRS) model. Charnes et al. ${ }^{1}$ proposed an input-oriented model and assumed CRS, while Banker et al. ${ }^{20}$ proposed a VRS model. With input-oriented DEA, the aim is to determine how much the input use of DMUs could be reduced by efficient use in order to achieve the same level of output. With output-oriented DEA, the DMUs are made efficient through increase in outputs using the same level of inputs. In CRS, increase or decrease in inputs or outputs results in a proportional change in them; however, this is not true for VRS. The linear programming of an inputoriented and output-oriented DEA model under CRS can be configured as under:

(i) Input-oriented

$$
\text { Minimize } \quad \theta-\varepsilon\left(\sum_{i=1}^{m} S_{j}^{-}+\sum_{r=1}^{s} S_{r}^{+}\right)
$$

such that

$$
\begin{aligned}
& \sum_{j=1}^{n} X_{i j} \lambda_{j}+S_{i}^{-}=\theta X_{i 0}, \\
& \sum_{j=1}^{n} Y_{r j} \lambda_{j}-S_{r}^{+}=Y_{r 0}, \\
& \lambda_{j} \geq 0 .
\end{aligned}
$$

(ii) Output-oriented

$$
\operatorname{Max.} \varphi+\varepsilon\left(\sum_{i=1}^{m} S_{i}^{-}+\sum_{r=1}^{s} S_{r}^{+}\right)
$$


such that

$$
\begin{aligned}
& \sum_{j=1}^{n} Y_{r j} \lambda_{j}-S_{r}^{+}=\varphi Y_{r 0}, \\
& \sum_{j=1}^{n} X_{i j} \lambda_{j}+S_{i}^{-}=X_{i 0}, \\
& \lambda_{j} \geq 0 .
\end{aligned}
$$

where $\lambda_{j}, S_{i}^{-}, S_{r}^{+} \geq 0$ and $\varepsilon>0, i=1,2, \ldots, m$ (inputs), $r=1,2, \ldots, s$ (outputs), $j=1,2, \ldots, n$ (DMUs), $\theta$ is the inefficiency, $\varphi$ the efficiency, $S_{i}^{-}$the input excess, $S_{r}^{+}$the output shortfall, $\lambda_{j}$ the weight for the $j$ th DMU, $X_{i j}$ the $i$ th input of the $j$ th DMU and $Y_{r j}$ is the $r$ th output of the $j$ th DMU.

If the constraint $\sum_{j=1}^{n} \lambda_{j}=1$ is added in both eqs (4) and (5), then above CRS model is converted to VRS model.

\section{Slacks-based DEA model}

The slacks-based DEA model was first proposed by Tone ${ }^{3}$. One of the main advantages of this model is that it deals directly with the input excess and output shortfall of the concerned DMU. This measure is unit invariant and monotone decreasing with respect to input excess and output shortfall. It is determined only by consulting the reference set of the DMU and is not affected by the whole dataset. According to Tone $^{3}$, the linear programming problem can be formulated as described below.

A particular DMU $\left(x_{0}, y_{0}\right)$ can be described as

$$
\begin{aligned}
& x_{0}=X \lambda+s^{-}, \\
& y_{0}=Y \lambda-s^{+},
\end{aligned}
$$

with $\lambda \geq 0, s^{-} \geq 0, s^{+} \geq 0$. The vectors $s^{-} \in R^{m}$ and $s^{+} \in R^{s}$ denote the input excess and output shortfall respectively, and are termed as slacks. An index $\rho$ is defined as follows

$$
\rho=\frac{1-\frac{1}{m} \sum_{i=1}^{m} s_{i}^{-} / x_{i 0}}{1+\frac{1}{s} \sum_{r=1}^{s} s_{r}^{+} / y_{r 0}}, 0<\rho \leq 1 .
$$

The below mentioned equation is formulated to estimate the efficiency of $\left(x_{0}, y_{0}\right)$.

$$
\text { Min. } \rho=\frac{1-\frac{1}{m} \sum_{i=1}^{m} s_{i}^{-} / x_{i 0}}{1+\frac{1}{s} \sum_{r=1}^{s} s_{r}^{+} / y_{r 0}} \text {, }
$$

such that

$$
\begin{aligned}
& x_{0}=X \lambda+s^{-}, \\
& y_{0}=Y \lambda-s^{+}, \\
& \lambda \geq 0, s^{-} \geq 0, s^{+} \geq 0 .
\end{aligned}
$$

By multiplying a scalar variable $t(>0)$ in both the denominator and numerator in eq. (9), $t$ is adjusted so that the denominator becomes 1 and this term is kept under constraints. Thus, eq. (9) becomes

$$
\text { Min. } \tau=t-1-\frac{1}{m} \sum_{i=1}^{m} t s_{i}^{-} / x_{i 0} \text {, }
$$

such that

$$
\begin{aligned}
& t+\frac{1}{s} \sum_{r=1}^{s} t s_{r}^{+} / y_{r 0}=1, \\
& x_{0}=X \lambda+s^{-}, \\
& y_{0}=Y \lambda-s^{+}, \\
& \lambda \geq 0, s^{-} \geq 0, s^{+} \geq 0 .
\end{aligned}
$$

Equation (10) is a nonlinear programming problem because it contains a nonlinear term $t s^{+}$. It is transformed into a linear program assuming $S^{-}=t s^{-}, S^{+}=t s^{+}, \Lambda=t \lambda$. Now eq. (10) becomes a linear program in $t, S^{+}, S$ and $\Lambda$ and can be written as

$$
\text { Min. } \tau=t-1-\frac{1}{m} \sum_{i=1}^{m} S_{i}^{-} / x_{i 0} \text {, }
$$

such that

$$
\begin{aligned}
& t+\frac{1}{s} \sum_{r=1}^{s} S_{r}^{+} / y_{r 0}=1, \\
& t x_{0}=X \Lambda+s^{-}, \\
& t y_{0}=Y \Lambda-s^{+}, \\
& \lambda \geq 0, s^{-} \geq 0, s^{+} \geq 0 .
\end{aligned}
$$

An optimal solution of $\operatorname{SBM}\left(\rho^{*}=\tau^{*}, s^{-*}=S / t, s^{+} *=\right.$ $\left.S^{+} / t, \lambda^{*}=\Lambda / t\right)$ is found after eq. (11). A DMU $\left(x_{0}, y_{0}\right)$ is said to be SBM-efficient if $\rho^{*}=1$. The DMU $\left(x_{0}, y_{0}\right)$ can be efficient by reducing the input excess and increasing the output shortfall as follows

$$
\begin{aligned}
& x_{0}^{*}=x_{0}-s^{-*}, \\
& y_{0}^{*}=y_{0}+s^{+} .
\end{aligned}
$$




\section{Metric approach of sensitivity analysis}

This approach utilizes the concepts of vector norm to determine the radius of stability. The data variation within the radius of stability will not affect classification of DMUs from efficient to inefficient status and vice versa ${ }^{21}$. The model given by Charnes et al. ${ }^{22}$ to estimate radius of stability is given below

Max. $\delta$

such that

$$
\begin{aligned}
& y_{r 0}=\sum_{j=1}^{n} y_{r j} \lambda_{j}-s_{r}^{+}-\delta d_{r}^{+}, \\
& x_{i 0}=\sum_{j=1}^{n} x_{i j} \lambda_{j}-s_{i}^{-}-\delta d_{i}^{+}, \\
& \sum_{j=1}^{n} \lambda_{j}=1,
\end{aligned}
$$

where $i=1,2, \ldots, m$ inputs; $r=1,2, \ldots, s$ outputs and $j=1,2, \ldots, n$ DMUs. All the variables, including $\delta$ are non-negative while $d_{r}^{+}$and $d_{i}^{-}$are fixed constants set to unity.

The optimal solution of $\delta^{*}$ can be obtained after solving eq. (13). The model (eq. (13)) is applicable to inefficient DMUs which will remain so after altering $y_{r 0}$ to $\left(y_{r 0}+\delta^{*}\right)$ and $x_{i 0}$ to $\left(x_{i 0}-\delta^{*}\right)$.

\section{Results and discussion}

The parameters of the SFA model were estimated using quasi-Newton optimization method available in the QLIM procedure (SAS-9.3; Table 1). Results show that helpers and technicians play a significant role in manufacturing, which is evident in both half-normal as well as exponential distribution. The estimated values for $\sigma_{u}$ were found to be 0.937 and 0.534 in half-normal and exponential distribution respectively, and both are significant at $1 \%$ level. This provides evidence to reject the null hypothesis that there is no technical inefficiency.

' $\gamma$ ' $\left[\sigma_{\mathrm{U}}^{2} /\left(\sigma_{\mathrm{V}}^{2}+\sigma_{\mathrm{U}}^{2}\right)\right]$ is a measure of technical inefficiency and it lies between 0 and 1. If it is close to zero, this indicates that deviations from the frontier may be due to noise and when it is close to 1 , deviations from the frontier can be attributed to technical inefficiency ${ }^{23,24}$. Here, the value of $\gamma$ for half-normal distribution is 0.69 , which implies that out of the total variation, $69 \%$ is due to technical inefficiency in the manufacturing system whereas $31 \%$ is due to stochastic errors. In case of exponential distribution only $40 \%$ variation is due to technical ineffi- ciency as $\sigma_{u}$ is significant in both the cases. Also, there is $69 \%$ variability due to technical inefficiency under halfnormal distribution.

An input-orientated DEA was carried out to determine whether farm machinery manufactures were operating under increasing returns to scale (IRS), CRS or decreasing returns to scale (DRS). The scale efficiency $\left(\mathrm{SE}_{n}=\right.$ $\mathrm{TE}_{\mathrm{CRSn}} / \mathrm{TE}_{\mathrm{VRSn}}$ ) was obtained for each manufacturer. When the value for $\mathrm{SE}_{n}$ is one, it indicates that the manufacturing unit is operating at an optimal scale and if $\mathrm{SE}_{n}<1$, it indicates that the manufacturing unit is scaleinefficient. Scale inefficiency may be due to the presence of either IRS or DRS. It does not provide information on whether the inefficiency is the result of IRS or DRS. Increasing or decreasing returns to scale can be identified for each manufacturer by running the input-oriented DEA (VRS) model by replacing the constraint $\sum_{j=1}^{n} \lambda_{j}=1$ by $\sum_{j=1}^{n} \lambda_{j} \leq 1$. This provides the technical efficiency under non-increasing returns to scale $\left(\mathrm{NIRS}_{n}\right)$. If technical efficiency under $\mathrm{NIRS}_{n}$ is equal to technical efficiency under $\mathrm{VRS}_{n}$, the manufacturer exhibits DRS. If technical efficiency under $\mathrm{NIRS}_{n}$ is not equal to technical efficiency under $\mathrm{VRS}_{n}$, the manufacturer exhibits $\mathrm{IRS}^{25}$.

The analysis showed that 74 out of 87 manufacturers showed IRS, which means proportional increase in ATO is more than proportional increase in inputs. Ten manufacturers showed CRS, which means that there is proportional increase in ATO with increase in inputs. Three manufacturers showed DRS, which indicates that the proportional increase in ATO was less than increase in inputs. If an increase in inputs results in proportional increase in outputs, the DMUs exhibit CRS. If an increase in inputs results in more than proportional increase in output, then it exhibits increasing returns to scale. If it is less than the proportional increase in outputs, the DMUs show decreasing returns to scale ${ }^{26}$. Thus, majority of manufacturers $(85.05 \%)$ showed IRS, less number of manufacturers (3.44\%) showed DRS and $11.49 \%$ manufacturers showed CRS (Figure 1). The reason that majority of manufacturers showed VRS was that there were variations in inputs like number of technicians, number of helpers and ATO. Also, there were variations in manufacturing technology. The number of tools/machinery used in manufacturing varied widely among the manufacturers. There were variations in tools like vertical milling centre (VMC) and computer numeric control (CNC) machines that were used for manufacturing agricultural implements.

SBM was applied to determine technical efficiency of farm machinery manufacturers and deal with the input excess and output shortfall. Figure 2 shows the technical efficiency of farm machinery manufacturers under SBM. There were ten efficient manufacturers under SBM, who were also efficient under CRS. These results are supported by Tone ${ }^{3}$, who demonstrated that SBM $\rho^{*}$ is not greater than CRS efficiency measure $\left(\theta^{*}\right)$, and a DMU is 
RESEARCH ARTICLES

Table 1. Estimates of the stochastic frontier model with inefficiency effects for farm machinery manufacturers

\begin{tabular}{|c|c|c|c|c|c|c|}
\hline \multirow[b]{2}{*}{ Variables } & \multicolumn{3}{|c|}{ Half normal } & \multicolumn{3}{|c|}{ Exponential } \\
\hline & Estimate & Standard error & $t$ Value & Estimate & Standard error & $t$ Value \\
\hline Intercept $\left(\beta_{0}\right)$ & $-0.885^{* *}$ & 0.264 & -3.35 & $-1.107 * *$ & 0.227 & -4.88 \\
\hline $\operatorname{TECH}\left(\beta_{1}\right)$ & $0.319^{*}$ & 0.147 & 2.16 & $0.318^{*}$ & 0.142 & 2.23 \\
\hline $\operatorname{HELP}\left(\beta_{2}\right)$ & $0.692 * *$ & 0.138 & 4.99 & $0.706 * *$ & 0.134 & 5.26 \\
\hline $\operatorname{SMAN}\left(\beta_{3}\right)$ & 0.162 & 0.306 & 0.53 & 0.163 & 0.296 & 0.55 \\
\hline $\operatorname{SERV}\left(\beta_{4}\right)$ & 0.337 & 0.282 & 1.19 & 0.307 & 0.268 & 1.15 \\
\hline $\operatorname{OSTA}\left(\beta_{5}\right)$ & 0.352 & 0.233 & 1.51 & 0.346 & 0.227 & 1.52 \\
\hline Sigma_v & $0.631 * *$ & 0.117 & 5.39 & $0.656 * *$ & 0.088 & 7.44 \\
\hline Sigma_u $u$ & $0.937 * *$ & 0.242 & 3.87 & $0.534 * *$ & 0.142 & 3.74 \\
\hline $\operatorname{Gama}(\gamma)$ & 0.69 & & & 0.40 & & \\
\hline
\end{tabular}

** and * indicate significance level at $1 \%$ and $5 \%$ respectively.

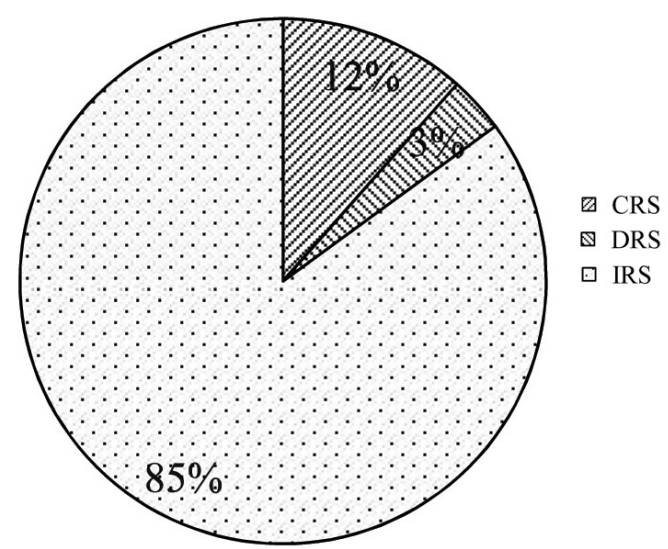

Figure 1. Farm machinery manufacturers with different rates of return.

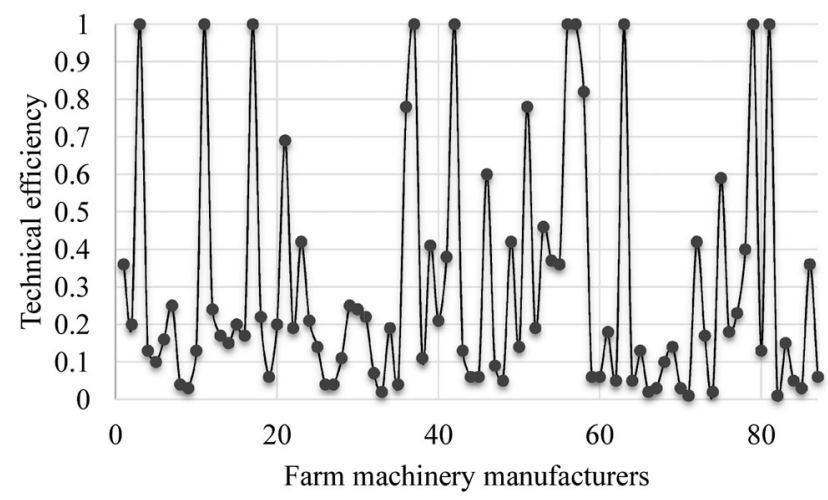

Figure 2. Technical efficiency of farm machinery manufacturers under slacks-based data envelopment analysis.

SBM-efficient if and only if it is CRS-efficient. The average technical efficiency was found to be 0.30 in SBM, whereas in CRS, it was 0.34.

The evaluated technical efficiency for all the farm machinery manufacturers under SBM along with scale efficiency and existing returns to scale is presented in Supplementary Table 1 . The number of efficient manufacturers was found to be 10 under SBM.
The input excess and output shortfall of inefficient farm machinery manufacturers in SBM is shown in Supplementary Table 2. These inefficient manufacturers can become efficient after reducing their input and increasing their ATO (Supplementary Table 3). It is evident that for majority of the manufacturers, the number of technicians and helpers played an important role in reducing the technical efficiency and ATO of farm machinery manufactures. It was also observed that only the number of technicians and number of helpers were significant. For instance, manufacturer - ' 1 ' will have to remove 13 technicians, 11 helpers, 5 office staffs and 2 service staff without increasing ATO to become efficient. Overall, it was found that on an average, a manufacturer has to increase ATO by INR 40.7 million and remove one salesman, four technicians, eight helpers, two office staff and one service staff to become efficient.

The sensitivity analysis for data variations in input and output was carried out using metric approach for all the 77 inefficient manufacturers and radius of stability $(\delta)$ was estimated. The estimated $\delta$ of inefficient manufacturers varied from 0 to 1.74 . The data variation in inputs and output with technical efficiency of each inefficient manufacturer is presented in the Supplementary Table 3. The technical efficiency of an inefficient manufacture was further evaluated using the transformed data in the presence of efficient manufacturers, so that the technical efficiency of the inefficient manufacturer can be evaluated relative to the best performing manufacturer. Results showed that variation in input and output within the estimated $\delta$ did not alter the group of efficient and inefficient manufacturers. The manufactures who were inefficient before data alterations, remained so after data alterations as well. The technical efficiency of manufacturers $(3,11$, $17,37,42,56,57,63,79$ and 81) was found to be efficient (technical efficiency $=1$ ) before and after data alteration within $\delta$ (Figure 3 ). The inefficient manufactures were found to remain so after change in inputs and outputs within $\delta$; not a single inefficient manufacturers became efficient. Thus, the classification was found to be robust against data alteration within $\delta$. 


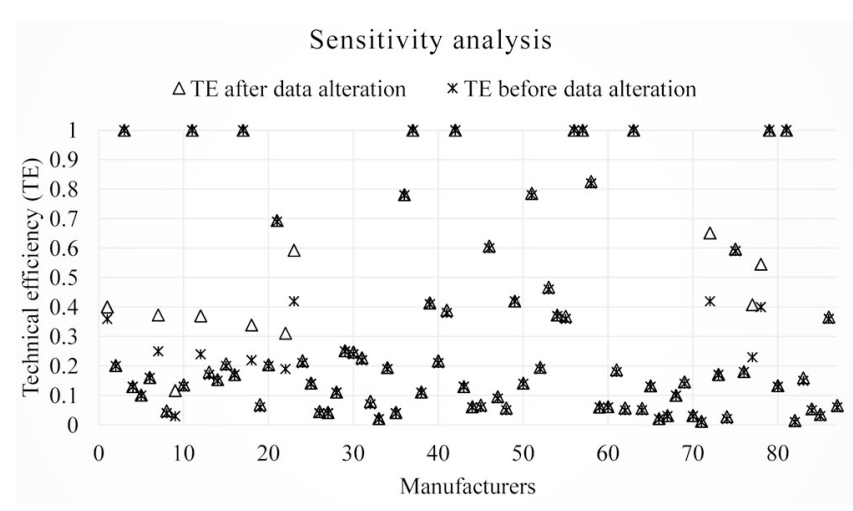

Figure 3. Technical efficiency of manufacturers before and after data alteration.

Results show that majority of manufacturers (86\%) were small and marginal, and at a lower scale with less efficiency. This is because small manufacturers have very basic and traditional workshop facility. They are unable to manufacture quality implements with higher production capacity and hence their ATO is at a lower scale. Medium and large manufacturers with advanced workshop facilities like computer numerical control, plasma cutter, vertical machining centre and skilled workforce can manufacture a variety of high capacity farm implements of superior quality and thus have higher ATO. Moreover, the farm machinery sector is season-based and small manufacturers are not capable of manufacturing more implements during off-season as they are unable to invest more capital. However, large manufacturers are capable of manufacturing during off-season too and well in time and thus make good profit.

\section{Conclusion}

The number of technicians and helpers was found statistically significant in affecting the technical inefficiency of farm machinery manufacturers. Evidence was found at $1 \%$ level of significance to reject the null hypothesis that there was no technical inefficiency among the manufacturers. The technical inefficiency measure $\gamma$ was estimated to be 0.69 , which implies that out of the total variation, $69 \%$ is the result of the technical inefficiency in the manufacturing system, whereas $31 \%$ is due to stochastic errors. Results indicate that farm implements are being manufactured with technical efficiency of $54.3 \%$ and $65.2 \%$ according to the half-normal distribution and exponential distribution respectively. Thus, it can be concluded that there is ample scope of increasing efficiency and profit by utilizing the same set of inputs and manufacturing technology. It was found that $85.05 \%$ of the manufacturers exhibited IRS, $3.44 \%$ DRS and $11.49 \%$ CRS. The average technical efficiency under SBM was found to be 0.30 . Sensitivity analysis of technical effi- ciency showed that the estimated radius of stability for inefficient manufacturers varied from 0 to 1.74 . The efficiency status of manufacturers were found to be robust against data alteration within the estimated radius of stability. On an average, a manufacturer has to increase ATO by INR 40.7 million and has to remove one salesman, four technicians, eight helpers, two office staff and one service staff to become efficient. Majority of manufacturers $(85.05 \%)$ exhibited IRS, which is good sign for the farm machinery manufacturing sector. Small and marginal manufacturers are at a lower scale with less efficiency due to unavailability of advanced workshop facilities, skilled workforce and lack of capital investment.

1. Charnes, A., Cooper, W. W. and Rhodes, E., Measuring the efficiency of decision making units. Eur. J. Oper. Res., 1978, 2(6), 429-444.

2. Cooper, W. W., Seiford, L. M. and Zhu, J., Data envelopment analysis: history, models, and interpretations. In Handbook on Data Envelopment Analysis, Springer, Boston, MA, 2011.

3. Tone, K., A slacks-based measure of efficiency in data envelopment analysis. Eur. J. Oper. Res., 2001, 130(3), 498-509.

4. Mehta, C. R., Chandel, N. S. and Senthilkumar, T., Status, challenges and strategies for farm mechanization in India. Agric. Mech. Asia, Africa, Latin America, 2014, 45(4), 43-50.

5. Anon., Sectoral paper on farm mechanization. Farm Sector Policy Department, NABARD Head Office, Mumbai, 2018.

6. Kumar, M., Dubey, A. K., Dubey, U. C., Bargale, P. C. and Ahmad, T., Quantification of agricultural mechanization for soybean-wheat cropping pattern in Bhopal region of India. Agric. Mech. Asia, Africa, Latin America, 2016, 47(1), 28-32.

7. Singh, R. S. and Kumar, M., Economic evaluation and mechanization index of selected cropping pattern in Madhya Pradesh. Econ. Aff., 2017, 62(3), 439-446.

8. Singh, D., Singh, S. P., Saxena, A. C., Biswas, H. S. and Saha, K P., Status of farm machinery manufacturers in Madhya Pradesh. Agric. Eng. Today, 2009, 33(1), 14-19.

9. Kumar, M. and Basu, P., Perspectives of productivity growth in Indian food industry: a data envelopment analysis. Int. J. Prod. Perform. Manage., 2008, 57(7), 503-522.

10. Nassiri, S. M. and Singh, S., Study on energy use efficiency for paddy crop using data envelopment analysis (DEA) technique. Appl. Energy, 2009, 86(7-8), 1320-1325.

11. Raju, S. K. and Kumar, D. N., Fuzzy data envelopment analysis for performance evaluation of an irrigation system. Irr. Drain., 2013, 62(2), 170-180.

12. Maity, C. K., Productivity potential and technical efficiency differences among the Indian framers. Int. J. Hum. Soc. Sci. Invent., 2015, 4(3), 01-06

13. Shekhar, H., Kundra, M. and Kumar, P., Trends in agricultural productivity: a state level analysis. Int. J. Appl. Res., 2017, 3(5), 641-645.

14. Mathur, R. N. and Ramnath, S. R., Efficiency in food grains production in India using DEA and SFA. Central Eur. Rev. Econ. Manage., 2018, 2(1), 79-101.

15. Malhotra, R., Performance analysis of food processing industries in Punjab using data envelopment analysis. Int. J. Econ. Manage. Sci., 2018, 7(5), 550.

16. Taleb, M., Khalid, R. and Ramli, R., Estimating the return to scale of an integer-valued data envelopment analysis model: efficiency assessment of a higher education institution. Arab J. Basic Appl. Sci., 2019, 26(1), 144-152. 


\section{RESEARCH ARTICLES}

17. Kumar, M., Tamhankar, M. B., Babu, V. B., Mehta, C. R. and Sahni, R. K., In Farm machinery manufacturers in Madhya Pradesh. Technical e-bulletin No. CIAE/AMD/2019/01, ICARCentral Institute of Agricultural Engineering, Bhopal, 2019.

18. Aigner, C., Lovell, C. A. K. and Schmidt, P., Formulation and estimation of stochastic frontier production function models. J. Econ., 1977, 6(1), 21-37.

19. Meeusen, W. and Broeck, J. V. D., Efficiency estimation from Cobb-Douglas production functions with composed error. Int. Econ. Rev., 1977, 18(2), 435-444.

20. Banker, R. D., Charnes, A. and Cooper, W. W., Some models for estimating technical and scale inefficiencies in data envelopment analysis. Manage. Sci., 1984, 30(9), 1078-1092.

21. Cooper, W. W., Seiford, L. M. and Tone, K., Data Envelopment Analysis, Springer Science and Business Media, New York, USA, 2007, 2nd edn, pp. 283-287.

22. Charnes, A., Haag, S., Jaska, P. and Semple, J., Sensitivity of efficiency calculations in the additive model of data envelopment analysis. Int. J. Syst. Sci., 1992, 23, 789-798.

23. Battese, G. E. and Corra, G. S., Estimation of a production frontier model: with application to the pastoral zone of Eastern Australia. Austr. J. Agric. Econ., 1977, 21(3), 169-179.
24. Coelli, T. J., Rao, D. S. P., O’Donnell, C. J. and Battese, G. E., An Introduction to Efficiency and Productivity Analysis, Springer Science and Business Media, USA, 2005.

25. Coelli, T., Rahman, S. and Thirtle, C., Technical, allocative, cost and scale efficiencies in Bangladesh rice cultivation: a nonparametric approach. J. Agric. Econ., 2002, 53(3), 607-626.

26. Benicio, J. and de Mello, J. C. S., Productivity analysis and variable returns of scale: DEA efficiency frontier interpretation. Procedia Comput. Sci., 2015, 55, 341-349.

ACKNOWLEDGEMENTS. We thank the Indian Council of Agricultural Research, New Delhi for financial support and the Director, Central Institute of Agricultural Engineering, Bhopal for guidance to carry out this work.

Received 30 April 2020; revised accepted 10 January 2021

doi: $10.18520 / \mathrm{cs} / \mathrm{v} 120 / \mathrm{i} 8 / 1350-1357$ 